British Journal of Economics, Management \& Trade
17(2): 1-9, 2017; Article no.BJEMT.33021
ISSN: 2278-098X
SCIENCEDOMAIN international
WwW.SCiencedomain.org

\title{
Measuring Services Quality: Tabuk Municipal
}

\author{
Saleh Hamed Alharbi ${ }^{1 *}$ and Omer Ahmed Sayed ${ }^{2}$ \\ ${ }^{1}$ Department of Management, Faculty of Business Administration, Tabuk University, Tabuk, \\ Saudi Arabia. \\ ${ }^{2}$ Department of Finance and Investment, Faculty of Business Administration, Tabuk University, \\ Tabuk, Saudi Arabia.

\section{Authors' contributions}

The two authors contributed at drafting and writing. Author OAS conducting the analysis. While author Alharbi looked for relevant articles and designed the Questionnaire and made the data collection and by joining efforts with author Sayed made the results interpretation. The recommendations were established based on several discussions between the two authors. Both authors read and gave their final approval of the version to be published.

Article Information

DOI: 10.9734/BJEMT/2017/33021

Editor(s):

(1) Chiang-Ming Chen, Department of Economics, National Chi Nan University, Taiwan. Reviewers:

(1) Marcos de Moraes Sousa, Instituto Federal Goiano, Universidade Federal de Goiás, Brazil. (2) Atilla Akbaba, Izmir Katip Celebi University, Turkey.

(3) Tarun Kumar Gupta, YMCA University of Science \& Technology, Faridabad, India. Complete Peer review History: http://www.sciencedomain.org/review-history/19036

Original Research Article

Received $27^{\text {th }}$ March 2017

Accepted $2^{\text {nd }}$ May 2017

Published $12^{\text {th }}$ May 2017

\begin{abstract}
This study evaluates service quality in Tabuk Municipality and tries to identify employee constraints of providing better service. The study used SERVPERF presented by Cronin and Taylor [2] (1992) to explore client perceptions of the service quality provided by municipal Tabuk. Interviews with Tabuk Municipality employees were then conducted, which focused on issues raised in the questionnaire analysis. Statistical analyses revealed a positive relationship between the tangible dimension and quality of service. Interviewees indicated that municipal employees require additional training to improve their skills in working with the public. Moreover, employees viewed incentives as an important avenue for improving the quality of services provided.
\end{abstract}

Keywords: Service quality; public sector; customer; Saudi Arabia. 


\section{INTRODUCTION}

Nowadays, civil service reforms have been reoriented towards consumers due to increasing awareness about the quality of services they receive. As government agencies need to evaluate and assess their quality of service from a different angel, the most useful indicator is from their customers. The literature presents many models for measuring service quality one of them is Service Quality Model (SERVQUAL) which submitted by Parasuraman et al [1] and also Service Performance model (SERVPERF) which is presented by Cronin and Tayler [2] (1992). The second model is seen as a development of the first. Therefore this research used SERVPERF model to determine how their clients perceive Tabuk Municipality quality of services. This instrument consists of five dimensions: tangible, reliability, responsiveness, assurance, and empathy. Qualitative data were used as a complementary to illuminating some issues raised by questionnaire survey that needed more investigation to be illustrated.

There are 16 Municipalities in Saudi Arabia supervised by the Ministry of Municipal and Rural Affairs. One of these is found in Tabuk which located in the North West of Saudi Arabia. The municipalities in Saudi Arabia (including Tabuk Municipality, the site of this study) were established to provide services to the public, including public sanitation, establishment licensing, etc. Given massive technology improvements and the growing increase in the population in Saudi Arabia, the public sector is under increasing pressure to demonstrate their services are being continuously improved; services quality has investigated by many researchers in the private content of Saudi Arabia in such telecommunications industry banking sector and healthcare. The Municipalities provide the first infrastructure services to the community and not previous study has found examine the quality of services at public sector in Saudi Arabia this research comes to explore the level of service quality as its objectives are twofold:

1. To examine the quality of municipal services provided by Tabuk Municipality from the client's point of view.

2. To analyze the constraints employees face in providing better services to their customers.

The rest of this paper is structured as follows. In the second section, we will review the literature about service quality. The third section will describe the methods and methodologies used. We analyze the findings in the fourth section and provide conclusions discussion, implication and limitation in the last part.

\section{REVIEW OF THE LITERATURE}

Much research has been conducted on the subject of service quality (SQ) since the 1980s (Mahfooz [3]; Ladhari [4]. Service Quality (SERVQUAL) consists of five dimensions: tangibles, reliability, responsiveness, assurance, and empathy. The instrument measures perceived service quality and customer expectations, and it includes 22 items. The first dimensions measures how the appearance of physical facilities and other equipment affects a client and is measured with four items. The second dimension assesses how organizations perform promised services to their customers and are measured with five items. The third dimension relates to how far employees are willing to go to deliver direct services to their customer and is measured with four items. The fourth dimension assesses employees' abilities and the degree to which they convey confidence and trust to customers, and is measured with four items. Finally, empathy is defined as the attention and consideration that is paid to clients and is measured with five items. The instrument reveals the difference between perception and expectation.

The SERVQUAL model that was developed by Parasuraman et al. [1] is based on the gap between expectation and perception. This model has been tested in many studies in different fields. The SERVQUAL model has been criticized for its long process to measure expectation, action perception and the difference between them (the gap of the quality of the service).

The applicability of SERVQUAL has been widely criticized, yet despite its perceived shortcomings, this model is still in use. One major critique is the gap score according to Cronin and Tylor [2] (1992). Teas [5], and [6] (1994) stated that the expectation is improper as articulated its definition, whereas Brady and Cronin [7] criticized SERVQUAL because its measurement of service quality focuses on the process of service delivery and ignores service outcomes. On the other hand, Adetunji et al [8]. stated that "Measuring the product outcome for services may be quite difficult; so service quality is usually 
measured by the quality of its delivery processes" (pp. 31-32). That is to say; there are many questions about using a gap score while it is hard to define expectation objectively as they stated that it should be measured directly straight by using a perception score. Other criticism surrounding SERVQUAL includes the controversy over the utilization of a gap score because the process for assessing service quality requires subtracting perception and expectation. Van Dyke et al. [9] contended there was insufficient evidence for measuring psychological constructs through a gap score.

Although SERVQUAL measurement has been widely applied in many fields, it has been criticized by different researchers. Buttle [10] pointed out criticism for SERVQUAL from both theatrical and operational side. Teaa [5] (1993) stated that the concept of "expectation" is loose and open to many interpretations. Moreover, Ladhari [4] said that "expectations have been variously defined as desires, want, what a service provider should offer...." (67), which means expectation can be interpreted differently by people where it may influence the assessment of service quality.

In contrast, Cronin and Taylor [2] (1992) and McAlexander et al. [11] argued that measuring perception in the SERVPERF model outperforms gap scores in the SERVQUAL model when it comes to evaluating service quality. Moreover, both Richard and Allaway [12] and Brady and Cronin [7] (2001) argued that the SERVQUAL model focuses on the process of service delivery whereas the quality of service measured by the outcomes rather than its process.

Cronin and Taylor [2] (1992) presented an alternative model to gauge the quality of service, the SERVPERF model, which only measures perception of service quality and uses the same five dimensions and 22 items. However, it does not measure expectation. Thus SERVPERF only measures the knowledge of actual service that received by the customer. This distinction provides a distinct advantage over SERVQUAL. Adetunji et al [8]. indicated that SERVPERF is more suitable for evaluating the quality of service than SERVQUAL as stated above. Moreover, empirical evidence presented by McDougall and Levesque [13] showed that measuring the quality of service using customer perceptions was more efficient than using a gap score to measure expectation and perceptions. Cornin and Taylor [2] (1992) emphasized that measuring perception of quality is more accurate to assess the service quality. Cronin and Taylor [2] (1992) stressed that SERVPERF based on measuring the actual performance of service quality, instead of the gap approach.

\section{RESEARCH METHODOLOGY AND DESIGN}

In this part, we will find a detailed analysis of the method which has been used to collect data, analyses them and the presentation of the findings. This study is a cross-sectional descriptive study of the clients and employees of Tabuk Municipality. Quantitative and qualitative research techniques were used. The questionnaire and interviews were selfcompletion ones: The respondents completed them without any assistance.

\subsection{Population and Sampling}

The population to be moved in this study was the clients of the Tabuk Municipality. Non-probability sampling was used which represents a group of sampling techniques that enable researchers to select units from a population that they are interested in studying. Respondents were selected using convenience sampling (availability) method due to a potentially infinite population. This means that clients were selected due to the ease with which they could be contacted. We use random sampling techniques to determine the minimum number required. We distributed more than 163 questionnaires, collecting 140 and analyzing 140 surveys. Questionnaires are distributed to male clients of the municipal in Tabuk only because there are no female customers. The researchers requested permission from municipal in Tabuk to engage consumers in the study through giving them questionnaires to fill them as they come to the municipal in Tabuk before they went out.

\subsection{Sources of Data and Data Collection Instruments}

The research used primary data which selected for respondents using questionnaires and an interview. The instruments of this study were constructed by research objectives and research questions. The main research instrument is a questionnaire which consists of 22 questions and contains five sectors that reflect the five dimensions of quality as defined by. Those dimensions are; assurance, empathy, reliability, 
responsiveness and tangibles. In the questionnaire, a demographic section was to obtain information about the respondents. Information gathered through questions related to the client' age, occupation, social status and education level. The instrument was adapted to this study is a cross-sectional descriptive study of the customers and employees of Tabuk Municipality and was translated into Arabic.

The researchers assume a reasonable validity of research instrument since the five quality dimensions used in the study, have been introduced by experienced scholars in the field of service quality. We assess the reliability of data collected using Cronbach's Alpha reliability test. The value of this test is (0.91) which is a reasonable figure that constitutes a high internal consistency. Therefore, we can safely conclude that the data used in this study are reliable. Permission was gained from the upper management of Tabuk Municipal. From the other hand, during the interview no probes have used to direct respondents, this is to investigate deeper understanding also give respondents their time to articulate their meaning, moreover, to validate respondents previous answer questions, probes were used in different ways, to minimize error and bias. Finally, at the interview participant were asked if they wish to add any relevant information they felt it is necessary. According to Nueman [14] 2006 indicating that reliability of qualitative research proposes that when another research conducted under similar conditions, the result will be the same, where validity means truthfulness.

Bryman and Bell [15] 2007 stated that "One of the chief ways in which quantitative research can prepare the ground for qualitative research" (p.649). The research starts with the first stage as quantitative, where the survey data had suggested that some issues, which needs more investigative to be explored with the service provider (employees who provide the service for the client). Therefore, to study some of the processes and relations surrounding the standard of quality of the services that provided to client in-depth a semi-structured interview was appropriate by following an interview guide. The sampling of the interviewees was selected through snowball by that an interviewee suggested his colleagues as an essential to the research, and then the interviews were stopped when no more information can be gained from the level of saturation was achieved. There are four different halls provide various services to the client. The employees who participate are those who have a direct contact with client that because they able to provide sufficient answer to consumer concern that rose on the survey analysis.

We use 5-points Likert scale starting from strongly agree, agree, neutral, disagree and strongly disagree. This choice comes because previous research has found that a five-point scale is readily comprehensible to respondents and enables them to express their views as mentioned by Marton-Williams [16] (1986). The value of means represents the five categories of Likert scale; this representation is displayed in Table 1.

Table 1. Representation of the ranges of means

\begin{tabular}{ll}
\hline Range & Representation \\
\hline $1-1.79$ & Strongly disagree \\
$1.8-2.59$ & Disagree \\
$2.6-3.39$ & Neutral \\
$3.40-4.19$ & Agree \\
$4.20-5$ & Strongly agree \\
\hline
\end{tabular}

\section{DATA ANALYSIS AND FINDINGS}

We used quantitative methods to analyze the data derived from the questionnaire to explore client perceptions of the service quality provided by municipal of Tabuk. Namely, we used ANOVA analysis and some descriptive statistical indicators such as mean and standard deviation.

\subsection{Demographic Variables}

We used a one-way ANOVA for demographic variables of participants, including social status, educational attainment, and the results of our ANOVA indicated is no significant difference in the sample regarding social status as illustrated in Table 2.

The results of our ANOVA indicated is no significant difference in the sample regarding educational attainment as illustrated in Table 3.

The results of our ANOVA indicated is no significant difference in the sample regarding job status as illustrated in Table 4.

The results of our ANOVA indicated is no significant difference in the sample regarding social status, educational attainment, and job status. 
Table 2. ANOVA

\begin{tabular}{llllll}
\hline & Sum of squares & df & Mean square & F & Sig. \\
\hline Between groups & .761 & 1 & .76 & 1.08 & 0.3 \\
Within groups & 96.85 & 138 & .70 & & \\
total & 97.61 & 139 & & & \\
\hline
\end{tabular}

Table 3. ANOVA

\begin{tabular}{llllll}
\hline & Sum of squares & df & Mean square & F & Sig. \\
\hline Between groups & 4.26 & 4 & 1.07 & 1.49 & 0.210 \\
Within groups & 92.50 & 129 & .72 & & \\
total & 96.76 & 133 & & & \\
\hline
\end{tabular}

Table 4. ANOVA

\begin{tabular}{llllll}
\hline & Sum of squares & df & Mean square & F & Sig. \\
\hline Between groups & .463 & 2 & .231 & 0.315 & 0.731 \\
Within groups & 96.29 & 131 & .735 & & \\
total & 96.76 & 133 & & & \\
\hline
\end{tabular}

Table 5. Level of service quality in Tabuk municipality

\begin{tabular}{llllll}
\hline Dimensions & Reliability & Validity & Mean & Standard deviation & Statement \\
\hline Tangibility & 0.72 & 0.52 & 3.77 & 0.76 & Agree \\
Reliability & 0.87 & 0.76 & 2.88 & 0.97 & Neutral \\
Responsiveness & 0.79 & 0.62 & 3.03 & 0.58 & Neutral \\
Assurance & 0.85 & 0.72 & 3.19 & 0.96 & Neutral \\
Empathy & 0.80 & 0.64 & 3.24 & 0.86 & Neutral \\
Overall & 0.94 & 0.88 & 3.72 & 0.84 & Agree \\
\hline
\end{tabular}

\subsection{Level of Municipal Service Quality in Tabuk}

The clients of Tabuk Municipality asked to rate the degree to which they agreed with five dimensions of service quality. The results (shown in the Table (5)) reflect the opinions of the respondents (Tabuk Municipality clients).

Table 5 shows that Tabuk Municipality performed at a mid-high level (agree on level) in the tangibility dimension and at an average level (neutral) in the remaining four dimensions. However, the overall score is at the mid-high level.

\subsection{Interview Analysis}

Eight interviews were conducted with employees in Tabuk Municipality. These employees were selected because they had direct contact with the public. The interview questions were constructed based on the challenges highlighted by questionnaire respondents.
One of the greatest challenges faced by survey respondents was related to reliability. Five of the interviewees (first, second, third, fourth, and sixth) agreed that some of the employees who meet with the public lack the skills required to deal with the public. For example, one respondent stated that:

"Meeting the public needs the one who has high skills" (P 1)

His colleague went on to say "employees should take training courses for how to deals with the public to improves their skills" (P 2). Another participant stated that "employees must take training to be a professional in dealing with the public" ( $P$ 6), this statement come parallel and match the response of participants about reliability dimension which says: employees have required skills and experiences for providing needed services, then answer this question came with average of 3.61 with is in neutral point. An employee who faces the public should have required skills to avoid low levels of public service quality. 
In the reliability dimension participants indicated that the municipality did not allow the public to file a request on their website so as to avoid the need to come to the municipality, as stated by the second participant who said that the "municipality should activate the system that allows citizen follow up their inquiry online and does not come here till it ready to collect" (P 2). In contrast, interviewed four thought the municipality should activate the system that allows the citizen to apply for their service online instated of coming in. Interviewee seven agreed with interviewer four, stating that meeting the public is difficult and residents should use to receive their service electronically without coming to the municipality.

The above answers of interviewees, in somehow, came to the average of the questionnaire samples about the question: does the municipality improve its services and develop the process of work on a regular basis. The average survey answer was 3.16, which is neutral but more closely to agree on the interval that starts with the mean of 3.40 .

In the reliability dimension, three participants indicated that the municipality does not have precise requirements for each service that citizens need. As a result, residents are more likely to complain:

"The requirements in Tabuk Municipality differ from other municipalities in other regions. It should be a unified system for all municipalities and train employees to use, as it is in the labor office and social affairs. In those departments, they have a consolidated requirement system; the demand here should be clear for citizen" p.4.

Interviewee four highlights the importance of clear requirements and standards, as is the practice in other service ministries. Interviewee eight indicated that managers always circulate between departments and every manager has his vision, requirements, and standards, which often differ from previous managers:

"There are no precise requirements for citizen and all procedures. One manager comes with his requirements for a service, and then another manager brings another need for the same service, which minimizes service quality." (P 8)

The majority of interviewees indicated that not paying allowance for meeting public may influence employees performance, which linked to four dimensions of service quality which reliability responsiveness, assurance, and empathy. The second participant said "the thing that employees evades from meeting public because bad behavior from some customers, employees should be well trained and have an allowance for meeting public" P.2. Meeting citizens in the service hall bothers employees. Thus employees do not like to work in jobs that have direct contact with citizen or customers, especially when they do not get the allowance. Another interviewee said, "The municipality should pay incentives for those who meet public" ( $P$ 3). Interviewee six agreed, adding another reason for decreased quality of service, namely the delay in paying some of their dues, as he said that " our payment for our overtime and contributions are often delayed, where it takes one year to reach us" ( $P$ 6). As a result, employees may not show excellent customer service; therefore the quality of service may decrease.

With regards to the tangible dimension, some participants indicated there is no reception at the municipality that answers questions and directs customer toward the department that is responsible for their service. Therefore citizens who are visiting the municipality for the first time frequently go to many halls to find his service provider. This, in turn, interrupts employees who must respond to requests not related to their department.

Furthermore, an interviewee suggested the municipality should provide a machine that generates numbers and lets a customer take their number and sit to wait their turn.

One obstacle that affects the assurance dimension is that not all employees have knowledge and understanding of all the procedures and requirements for his department services, and are thus unable to confidently answer all questions that customer ask Interviewee eight added that when employees fail to respond questions related to his office, this may affect the confidence of customers.

\section{DISCUSSION AND CONCLUSION}

This article sought to quantify the quality of service provided by the municipality of Tabuk in Saudi Arabia and to understand the obstacles to improved service provision. The data were collected in two stages. The first stage included a questionnaire and the second stage used 
interviews with employees to find their barriers to improving their services. The statistical analyses reveal a positive relationship between the tangible dimension and quality service, whereas the other dimensions are neutral. There were no significant differences in jobs status, social status, and education level.

The interview analysis showed that employees face several constraints. Employees need to improve their skills to meet the public, which concurs with the findings of Al-Fawzan [17] (2005), who found that Saudi employees need to be trained to improve their skills. Al-Ali et al. [18] (2011) stated that intensive training program should be provided to employees to improve their skills, in turn, contribute to increasing service quality level, as this is in line with Alashari [19] (2012) result about public sector in Jeddah. Moreover, the Saudi Minister of Civil Service indicated that the Ministry of Civil Service adopted many initiatives for developing public employee's skills Alryaid newspaper [20] (2013). In this matter Idris [21] 2007 stated that Saudi Arabia faces some challenges in employees skills, as it mentioned by Assad 2002 cited in Branine and Pollard [22] 2010 stated that management in Arab countries has "too much centralization overbearing bureaucracy, poor communications, lack of management skills and unrealistic performance issues" (p.721).

Furthermore, several studies in the context of Saudi Arabia presented a similar result as they found that the customer care needs to have full knowledge to answer customers' questions such as Kadassah [23], [24] (2015, 2017). Moreover, the results of this study show that employees lack knowledge about the procedures and requirements for fully answering customer queries, a finding that is in line with Al-Fawzan [17] (2005), who likewise found that employees lacked the knowledge to answer customer questions. The finding of Jannadi et al. [25] (2000) study indicate that employees possess shortage of knowledge as they recommend that managers should spend some time with frontline staff for the purpose of improving their knowledge to fully accomplish customer requirements. Another case was that clarity of requirements and standards this find come in line with Jannadi [25] who indicated the procedure and requirement for each service should be unified at all branches then said "not allow managers of individual branches to make significant changes in procedures and policies as consumers may not receive the same level of service quality across the branches" (129).
Another finding of this research was in line with Albarahim [26] (2013) stated employers need to activate electronic services, and that the link between the municipality and other ministries is important for improving services. Alshwaier [27] (2010) indicated that the government of Saudi Arabia should work to activate e-government, which in turn would contribute to further development of the nation.

\section{IMPLICATIONS}

The result of this study provides important implications for practitioners as encourage and emphases them to exert the effort to improve a level of services as empirical studies found that the quality of service can be enhanced when the employees are highly skilled. Therefore, a practitioner can make emphases to organizations that they should train their staff for the reason of improving their skills or to heighten the process of accepting people into jobs because this, in turn, will enhance a quality of service which can help organizations for improving their reputation and income as well. Moreover, manager and companies owner needs to convert from traditional ways for providing services to the client to electronic services which help all parties (clients, organizations, and community) of saving money and times. Likewise, organizations should instead of waste time, and effort to both employees and client should assign at the front desk that thoroughly knowledgeable about all services and that their organizations have. Therefore public sector is recommended to build a partnership with private sector and benefit from their procedure as having precedence over the public sector or may exchange employees with them that may help to improve organization culture in public sector. On the other hand, the academic can investigate the causes of mentioned issues above and propose solutions to policymaker and practitioner and raise their awareness of how avoiding these matters.

\section{LIMITATION AND FURTHER RESEARCH}

This study was the first to utilize the SERVPERF model in the public sector in Saudi Arabia; however, it had several limitations. First, these findings are from the public sector in the Tabuk region, which may not apply to private or forprofit organizations, second, the data were collected only from the municipality. Collecting data from more than one public sector might have produced different results. 
Further research could measure customer satisfaction, as this study focused on quality service.

\section{COMPETING INTERESTS}

Authors have declared that no competing interests exist.

\section{REFERENCES}

1. Parasuraman A. Zeithaml V, Berry LA. A conceptual model of service quality and its implications for future; 1985.

2. Cronin JJ, Taylor SA. Measuring service quality: Are re-examination and extension. Journal of Marketing. 1992; 56(3):55-68.

3. Mahfooz Y. The relationship between service quality and customer satisfaction in hypermarkets of Saudi Arabia. International Journal of Marketing Studies. 2014;6(4):10-22.

4. Ladhari L. Alternative measures of service quality: A review, Managing Service Quality. An International Journal. 2008;18(1):65-86.

5. Teas RK. Expectation, performance evaluation and consumer perceptions of quality. Journal of Marketing. 1993;57(4):18-34.

6. Teas RK. Expectation as a comparison standard in measuring service quality: An assessment of a reassessment. Journal of Marketing. 1994;58(1):132-139.

7. Brady M, Cronin J. Some new thoughts on conceptualizing perceived service quality: A hierarchical approach. Journal of Marketing. 2001;65(3):34-49.

8. Adetunji $O$, Yadavalli VSS, Malinda A. Assessment of the quality of service provided by national regulatory institution. South African Journal of Industrial Engineering. 2013;24(1):29-49.

9. Van Dyke TP, Prybutok VR, Kappelman LA. Cautions on the use of Servqual measure to assess the quality of information system services. Decision Science. 1999;30(3):877-897.

10. Buttle F. Servqual: Review, critique, research agenda. European Journal of Marketing. 1996;30(1):8-32.

11. McAlexander JH, Kaldenberg DO, Koenig HF. Service quality measurement: The examination of dental practices sheds more light on the relationship between service quality, satisfaction, and purchase intention in a health care setting. Journal of Health Care Marketing. 1994;14(3):34-40.

12. Richard MD, Allaway AW. Service quality: Insights and managerial implications from the frontier. In: Rust, R. T., Oliver, R. L., editors. Service Quality: New Directions Theory and Practice. Thousand Oaks, CA: Sage Publications. 1993;1-19.

13. Neuman L. Social research methods: Qualitative and Quantitative Approaches. (6th End), 2006 Boston, Allyn, and Bacon. Research, Journal of Marketing. 1985;49(4):41-50.

14. McDougalla GHG, Levesque TJ. A revised view of service quality dimensions: An empirical investigation. Journal of Professional Services Marketing. 1995;11(1):189-210.

15. Bryman A, Bell E. Business research methods, 2ed. OXFORD university press. Oxford, New York; 2007.

16. Marton-Williams J. Questionnaire design, in consumer market research Handbook, Robert Worcester and John Downham (Eds). McGraw-Hill Book Company, London; 1986.

17. Al-Fawzan MA. Assessing service quality in a saudi bank. Journal of King Saudi University. 2005;18(1):101-115.

18. Al-Ali A, Khurshid M, Nasir N, Al-Ali H. Measuring the service quality of mobile phone companies in Saudi Arabia. Journal of King Saudi University. 2011;22(2):43-55.

19. Alshwaier KM. E-Government transactions in Kingdom of Saudi Arabia. 21 Conference of the Arabic Union for Libraries and information. Alam. Lebanon.

20. Al Riyadh Newspaper; 2013. Available:http://www.alriyadh.com/819815 Accessed 20/ 07/ 2016.

21. Idris A. Cultural barriers to improved organizational performance in Saudi Arabia. SAM Advanced Management Journal. 2007;72(2):36-53.

22. Branine $M$, Pollard D. Human resource management with Islamic management principles. Personnel Review. 2010;39(6):712-727.

23. Kadasah NA, Ageel MA. The level of service quality dimensions of the banking system in Jeddah, Saudi Arabia. International Review of Management and Business Research. 2015;4(4):1044-1059.

24. Kadasah NA. An Evaluation of Service Quality of a Telecommunication Company in Saudi Arabia using SERVPERF Scale. 
International Review of Management and Business Research. 2017;6(1):162-171.

25. Jannadi OA, Assaf S, Maghraby HM, AlTagged HA. Service quality gaps analysis at SECO-East, Saudi Arabia. Journal of Energy Engineering. 2000; 126(3):116-131

26. Al-Brahim A. Dealing with the public with good and different moods requires patience and incentives motivated largest. Al Riyadh Newspaper; 2013.

27. Alashari AD. Saudi citiczen feeling about dealy interaction with services in public sector. Journal King Abdualziz University, Economic and Management. 2012;26(1):113-175.

(c) 2017 Alharbi and Sayed; This is an Open Access article distributed under the terms of the Creative Commons Attribution License (http://creativecommons.org/licenses/by/4.0), which permits unrestricted use, distribution, and reproduction in any medium, provided the original work is properly cited.

Peer-review history:

The peer review history for this paper can be accessed here: http://sciencedomain.org/review-history/19036 